\title{
Epidemiología molecular de epizootias de rabia en Colombia, 1994-2002: evidencia de rabia humana y canina asociada con quirópteros
}

\author{
Andrés Páez ${ }^{1,2}$, Constanza Nuñez ${ }^{3}$, Clemencia García ${ }^{1}$, Jorge Boshell ${ }^{1}$ \\ ${ }^{1}$ Laboratorio de Virología, Instituto Nacional de Salud, Bogotá, D.C., Colombia. \\ 2 Departamento de Ciencias Básicas, Universidad de La Salle, Bogotá, D.C., Colombia. \\ ${ }^{3}$ Laboratorio de Virología, Universidad del Valle, Cali, Colombia.
}

Tres brotes de rabia canina han sido informados en Colombia durante las pasadas dos décadas, uno de los cuales aún ocurre en la Región Caribe. Los otros dos ocurrieron en el departamento de Arauca y en la Región Central (departamentos de Boyacá y Cundinamarca) hasta 1997. Con la finalidad de investigar las relaciones filogenéticas existentes entre los virus rábicos aislados en las regiones mencionadas, se empleó la técnica de RT-PCR para obtener fragmentos de ADN de 902 nucleótidos complementarios a una región del ARN rábico codificante para el endodominio de la proteína $\mathrm{G}$, para una parte de la proteína $\mathrm{L}$, fragmentos que, además, contienen la región intergénica no codificante G-L. Los amplificados fueron secuenciados y agrupados en árboles filogenéticos. Los resultados mostraron la existencia de tres grupos de virus. Los virus rábicos pertenecientes a la variante genética colombiana I fueron aislados exclusivamente en el departamento de Arauca y la Región Central colombiana hasta 1997 y, aparentemente, se encuentran extintos. Los virus rábicos pertenecientes a la variante genética colombiana II fueron aislados exclusivamente en la Región Caribe, en donde actualmente su tranmisión continúa. Un tercer grupo se compone de variantes rábicas originarias de quirópteros, que fueron aisladas de dos murciélagos insectívoros, tres perros y un humano. Con este trabajo se estableció una asociación entre los quirópteros y la rabia en perros y humanos en Colombia, lo cual los muestra como reservorios de importancia en salud pública.

Palabras clave: rabia, epidemiología molecular, quiróptero, virus, filogenia, RT-PCR.

Molecular epidemiology of rabies epizooties in Colombia, 1994-2002: evidence of human and canine rabies associated with bats

Three urban rabies outbreaks have been reported in Colombia during the last two decades, one of which is ongoing in the Caribbean region (northern Colombia). The earlier outbreaks occurred almost simultaneously in Arauca (eastern Colombia) and in the Central region, ending in 1997. Phylogenetic relationships among rabies viruses isolated from the three areas were based on a comparison of cDNA fragments coding for the endodomain of protein $G$ and a fragment of $L$ protein obtained by RT-PCR. The sequenced amplicons which included the G-L intergenic region contained 902 base pairs. Phylogenetic analysis showed three distinct groups of viruses. Colombian genetic variant I viruses were isolated only from Arauca and the Central region, but are now apparently extinct. Colombian genetic variant II viruses were isolated in the Caribbean region and are still being transmitted in that area. The third group of bat rabies variants were isolated from two insectivorous bats, three domestic dogs and a human. This associates bat rabies virus with rabies in Colombian dogs and humans, and indicates bats to be a rabies reservoir of public health significance.

Key words: rabies, molecular epidemiology, bats, virus, phylogeny, RT-PCR. 
La rabia es causada por virus altamente neurotrópicos del género Lyssavirus, de la familia Rhabdoviridae (1). El virión contiene genoma compuesto por ARN de polaridad negativa, no segmentado y de cadena sencilla compuesto por cerca de 12.000 nucleótidos y que codifica cinco proteínas estructurales $(2,3)$. Los reservorios de la rabia pertenecen a especies de los órdenes carnívora y quiróptera, los cuales transmiten los virus a otros mamíferos, incluidos los humanos. La rabia ocurre de dos maneras epizootiológicas diferentes: 1) la rabia urbana, con el perro doméstico como el principal reservorio y transmisor y, 2) la rabia silvestre con diferentes especies silvestres como el zorro, el coyote, el chacal, los quirópteros y otros, que actúan como reservorios y transmisores. Ambas formas epizootiológicas de la rabia ocurren en algunos países latinoaméricanos, incluido Colombia $(4,5)$, aunque en otros como Chile la rabia urbana se encuentra controlada desde $1982(6,7)$. De los 1.088 casos de rabia urbana que se registraron en el Ministerio de Salud de Colombia entre enero de 1992 y diciembre de 2002, 1.046 fueron infecciones en perros y 42 en humanos $(4,5)$. EI $95 \%$ del total de casos puede agruparse en tres regiones geográficas: departamento de Arauca (61 casos), la Región Central (246 casos) y la Región Caribe (719 casos). Los 62 casos adicionales se encuentran distribuidos en 15 departamentos del territorio colombiano $(4,5)$. Los brotes de rabia en el departamento de Arauca y en la Región Central finalizaron en 1997, mientras que en la Región Caribe el brote de rabia urbana, aunque se encuentra disminuido significativamente en 2002 ( 16 casos de rabia en perros en el periodo enerodiciembre), no ha sido controlado totalmente. La finalidad del presente estudio fue investigar las relaciones filogenéticas existentes entre los virus de rabia aislados en el departamento de Arauca y las Regiones Central y Caribe colombianas. En el estudio se incluyeron también dos cepas aisladas

$\overline{\text { Correspondencia: }}$

Andrés Páez, Laboratorio de Virología, Instituto Nacional de Salud, Avenida calle 26 No. 51-60, Bogotá, D.C., Colombia Tel: (571) 220 7700, ext. 439 y 549; Fax: (571) 2200928 apaezm@hemagogus.ins.gov.co

Recibido: 02/08/02; aceptado: 03/02/03 en murciélagos insectívoros en alrededores de la ciudad de Cali en 1995 y 2000. Para lograr los objetivos se utilizaron técnicas de epidemiología molecular como el aislamiento de ARN, RT-PCR, secuenciación de ADN complementario y análisis filogenético, las cuales se describen a continuación. Estudios similares en rabia han servido para elucidar las dinámicas de transmisión a nivel geográfico y entre diferentes especies animales en países como Francia (8), Canadá (9), Suráfrica (10), Venezuela (11), Estados Unidos (1214), Tailandia (15) e Israel (16) y, más recientemente en Brasil (17) y Trinidad (18).

\section{Materiales y métodos}

\section{La muestra de estudio}

El estudio incluyó 70 cepas de rabia cuyo origen geográfico se muestra en la figura 1 y el cuadro 1. Las 70 cepas están distribuidas de la siguiente manera: 68 cepas de rabia urbana ( 62 aisladas de perros y 6 de humanos) y 2 cepas aisladas de murciélagos insectívoros de las especies Eptesicus braziliensis y Molossus molossus en alrededores de la ciudad de Cali. Las 68 cepas de rabia urbana fueron aisladas en el periodo entre agosto de 1994 y marzo de 2002, durante los brotes de rabia urbana en Arauca (8 cepas) y las Regiones Central ( 15 cepas) y Caribe ( 45 cepas). Los aislamientos rábicos mencionados fueron recuperados en el Laboratorio de Virología del Instituto Nacional de Salud de Bogotá por ensayos de inmunofluorescencia directa y prueba biológica como recomienda la Organización Mundial de la Salud (19). De cada aislamiento se hizo un pasaje en 10 ratones ICR machos de 21 días de edad (20), cuyos cerebros infectados fueron almacenados $\mathrm{a}-80^{\circ} \mathrm{C}$ en el banco de virus rábicos.

\section{Extracción de ARN total}

Este proceso se hizo según lo descrito (20). Brevemente, $100 \mathrm{mg}$ de cerebro de ratón ICR correspondiente al pasaje de cada cepa se disolvió en $0,75 \mathrm{ml}$ de trizol (Gibco BRL) y extraido una vez con $0,25 \mathrm{ml}$ de cloroformo. El ARN total se precipitó con un volumen de alcohol isopropílico al $80 \%$, se lavó con $0,5 \mathrm{ml}$ de alcohol etílico y se resuspendió en $50 \mu \mathrm{l}$ de $0,1 \%$ dietilpirocarbonato (DEPC) en agua destilada. 


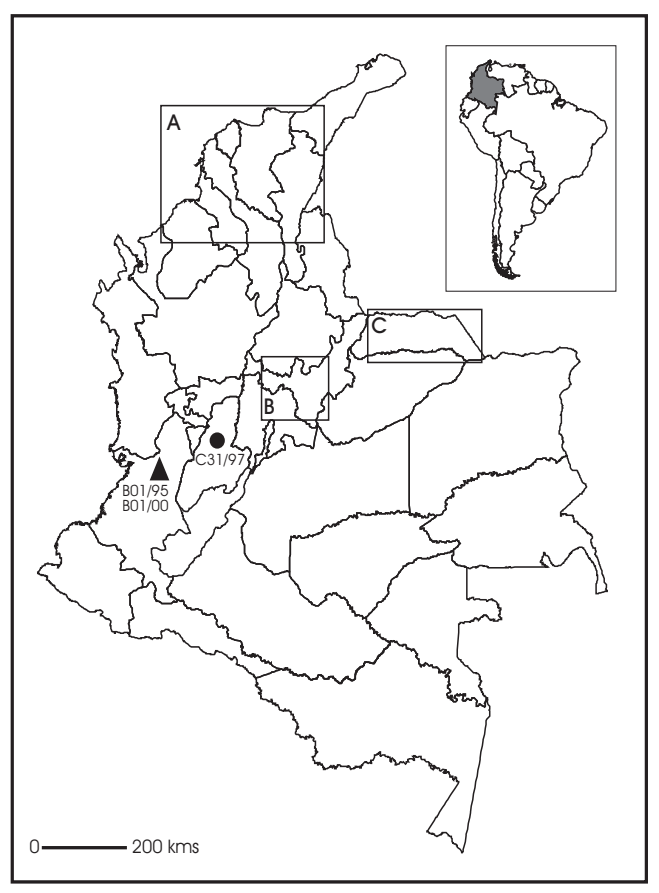

\section{Convenciones}

Círculo $=$ canino

Cuadrado $=$ humano

Triángulo $=$ murciélago insectívoro

Azul = variante genética colombiana l

Rojo=variante genética colombiana II

Negro $=$ variantes de rabia de quirópteros
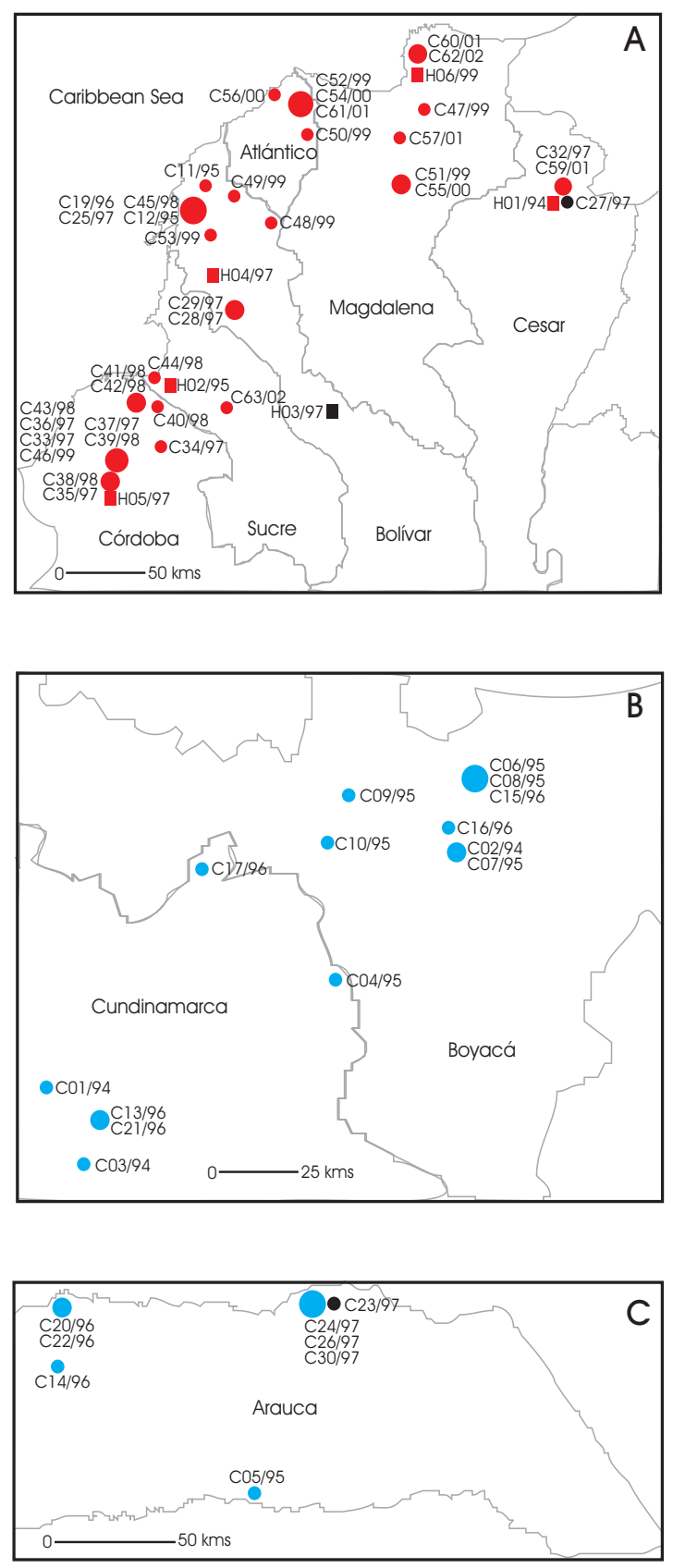

Figura 1. Mapa de Colombia en el cual se muestra la localización geográfica de los lugares en donde las cepas de rabia estudiadas fueron aisladas. A: Región Caribe; B: Región Central; C: Departamento de Arauca. Los símbolos y colores identifican la especie del hospedero y la variante genética de los virus. Para mayor claridad, los prefijos $\mathrm{C}$ (canino), $\mathrm{H}$ (humano) y $\mathrm{B}$ (murciélago) fueron añadidos al número de cada cepa. El número que sigue a la barra inclinada indica el año de aislamiento. 
Cuadro 1. Relación del origen geográfico, especie hospedera y fecha de aislamiento de las cepas rábicas estudiadas.

\begin{tabular}{|c|c|c|c|}
\hline Cepa & Origen geográfico & Especie hospedera & Fecha de aislamiento \\
\hline H01/94 & Valledupar, Cesar & Humano & Agos-1994 \\
\hline $\mathrm{C} 01 / 94$ & Subachoque,Cundinamarca & Canino & Sept-1994 \\
\hline $\mathrm{C} 02 / 94$ & Soracá, Boyacá & Canino & Noviembre1994 \\
\hline $\mathrm{CO3/94}$ & La Calera, Cundinamarca & Canino & Dic-1994 \\
\hline C04/95 & Villapinzón, Cundinamarca & Canino & Feb-1995 \\
\hline C05/95 & Puerto Rondón, Arauca & Canino & Feb-1995 \\
\hline C06/95 & Cómbita, Boyacá & Canino & Mar-1995 \\
\hline C07/95 & Soracá, Boyacá & Canino & Abr-1995 \\
\hline C08/95 & Cómbita, Boyacá & Canino & Abr-1995 \\
\hline B01/95 & Cali, Valle del Cauca & M. molossus & Jun-1995 \\
\hline C09/95 & Villa de Leyva, Boyacá & Canino & Jul-1995 \\
\hline C10/95 & Ráquira, Boyacá & Canino & Jul-1995 \\
\hline H02/95 & Sincelejo, Sucre & Humano & Jul-1995 \\
\hline C11/95 & Santa Rosa, Bolívar & Canino & Oct-1995 \\
\hline C12/95 & Cartagena, Bolívar & Canino & Nov-1995 \\
\hline $\mathrm{C} 13 / 96$ & Sopó, Cundinamarca & Canino & Abr-1996 \\
\hline C14/96 & Fortul, Arauca & Canino & Abr-1996 \\
\hline C15/96 & Cómbita, Boyacá & Canino & May-1996 \\
\hline C16/96 & Tunja, Boyacá & Canino & Jun-1996 \\
\hline C17/96 & Simijaca, Cundinamarca & Canino & Jun-1996 \\
\hline C19/96 & Cartagena, Bolívar & Canino & Jun-1996 \\
\hline C20/96 & Saravena, Arauca & Canino & Jul-1996 \\
\hline $\mathrm{C} 21 / 96$ & Sopó, Cundinamarca & Canino & Jul-1996 \\
\hline $\mathrm{C} 22 / 96$ & Saravena, Arauca & Canino & Sept-1996 \\
\hline $\mathrm{C} 23 / 97$ & Arauca, Arauca & Canino & Ene-1997 \\
\hline C24/97 & Arauca, Arauca & Canino & Feb-1997 \\
\hline C25/97 & Cartagena, Bolívar & Canino & Feb-1997 \\
\hline C26/97 & Arauca, Arauca & Canino & Feb-1997 \\
\hline $\mathrm{C} 27 / 97$ & Valledupar-Cesar & Canino & Feb-1997 \\
\hline C28/97 & El Carmen, Bolívar & Canino & Feb-1997 \\
\hline C29/97 & El Carmen, Bolívar & Canino & Feb-1997 \\
\hline C30/97 & Arauca, Arauca & Canino & Mar-1997 \\
\hline C31/97 & Ibagué, Tolima & Canino & Abr-1997 \\
\hline $\mathrm{H} 03 / 97$ & Puerto Rico, Bolívar & Humano & Ago-1997 \\
\hline C32/97 & Valledupar, Cesar & Canino & Ago-1997 \\
\hline $\mathrm{C} 33 / 97$ & Cereté, Córdoba & Canino & Sept-1997 \\
\hline C34/97 & Ciénaga de Oro, Córdoba & Canino & Sept-1997 \\
\hline $\mathrm{H} 04 / 97$ & San Jacinto, Bolívar & Humano & Oct-1997 \\
\hline C35/97 & Montería, Córdoba & Canino & Oct-1997 \\
\hline H05/97 & Montería, Córdoba & Humano & Oct-1997 \\
\hline C36/97 & Cereté, Córdoba & Canino & Oct-1997 \\
\hline C37/97 & Cereté, Córdoba & Canino & Nov-1997 \\
\hline C38/98 & Montería, Córdoba & Canino & Ene-1998 \\
\hline C39/98 & Cereté, Córdoba & Canino & Ene-1998 \\
\hline C40/98 & Momil, Córdoba & Canino & Feb-1998 \\
\hline C41/98 & Purísima, Córdoba & Canino & Jun-1998 \\
\hline $\mathrm{C} 42 / 98$ & Purísima, Córdoba & Canino & Jun-1998 \\
\hline $\mathrm{C} 43 / 98$ & Lorica, Córdoba & Canino & Jul-1998 \\
\hline C44/98 & Aserradero,Córdoba & Canino & Abr-1998 \\
\hline C45/98 & Cartagena, Bolívar & Canino & Oct-1998 \\
\hline C46/99 & Cereté, Córdoba & Canino & Feb-1999 \\
\hline H06/99 & Ciénaga, Magdalena & Humano & Feb-1999 \\
\hline C47/99 & Sevilla, Magdalena & Canino & Ago-1999 \\
\hline $\mathrm{C} 48 / 99$ & Barranca Nueva, Bolívar & Canino & Ago-1999 \\
\hline C49/99 & Estanislao, Bolívar & Canino & Ago-1999 \\
\hline C50/99 & Malambo, Atlántico & Canino & Ago-1999 \\
\hline C51/99 & Retén, Magdalena & Canino & Ago-1999 \\
\hline C52/99 & Barranquilla, Atlántico & Canino & Sept-1999 \\
\hline C53/99 & San Juan, Bolívar & Canino & Sept-1999 \\
\hline C54/00 & Barranquilla, Atlántico & Canino & Ene-2000 \\
\hline $\mathrm{C} 55 / 00$ & Retén, Magdalena & Canino & Ene-2000 \\
\hline $\mathrm{C} 56 / 00$ & Puerto Colombia, Atlántico & Canino & Ene-2000 \\
\hline B01/00 & Cali, Valle del Cauca & E. braziliensis & Sept-2000 \\
\hline C57/01 & Sierra Nevada, Magdalena & Canino & Feb-2001 \\
\hline C58/01 & Soledad, Atlántico & Canino & Mar-2001 \\
\hline C59/01 & Valledupar, Cesar & Canino & Abr-2002 \\
\hline $\mathrm{C} 60 / 01$ & Ciénaga, Magdalena & Canino & Jun-2001 \\
\hline $\mathrm{C} 61 / 01$ & Barranquilla, Atlántico & Canino & Jul-2001 \\
\hline C62/02 & Ciénaga, Magdalena & Canino & Mar-2002 \\
\hline $\mathrm{C} 63 / 02$ & Sincé, Sucre & Canino & Feb-2002 \\
\hline
\end{tabular}




\section{Iniciadores}

Un par de iniciadores conocido como $\mathrm{G}-\mathrm{L}(8,10)$ fue utilizado para amplificar por RT-PCR un fragmento de 902 nucleótidos, el cual codifica para el endodominio de la proteína $\mathrm{G}$ (aminoácidos 447 al 525 de la proteína G), y también para los aminoácidos 1 al 35 de la proteína L. El mencionado fragmento también contiene la región intergénica no codificante conocida como pseudogen Psi (21). El iniciador G de sentido positivo, tiene la secuencia 5' GACTTGGGTCTCCCAACTGGGG 3' y alínea con los nucleótidos 4665 al 4687 de ARN rábico. El iniciador $L$ de sentido negativo tiene la secuencia 5' CAAAGGAGAGTTGAGATTGTAGTC 3'y alínea con los nucleótidos 5543 al 5566 del ARN rábico $(8,10,21,22)$.

\section{RT-PCR}

El procedimiento de RT-PCR fue realizado como ya está descrito en detalle (20). Brevemente, se agregaron $5 \mu$ de la preparación de ARN total a 1 $\mu l$ del iniciador $\mathrm{G}$ (correspondiente a $150 \mathrm{ng}$ de éste) y se incubó a $65^{\circ} \mathrm{C}$ por 2 minutos. Posteriormente, la reacción de transcripción reversa fue llevada a cabo en un volumen de 20 $\mu$ a $42{ }^{\circ} \mathrm{C}$ durante 60 minutos. La amplificación por PCR fue hecha utilizando los iniciadores $G$ y $\mathrm{L}$ utilizando $2 \mu \mathrm{l}$ de la mezcla de la reacción de retrotranscripción, en un volumen total de $50 \mu \mathrm{l}$, en un termociclador Perkin Elmer, utilizando las condiciones de temperatura ya señaladas (20). A lo largo de todo el proceso de extracción del ARN total y RT-PCR, además de las cepas rábicas en estudio, se incluyeron controles positivos y negativos que fueron, respectivamente, material encefálico infectado con el virus rábico Pasteur (PV) y material encefálico de ratón normal.

\section{Secuenciación del ADN}

El producto de PCR fue sometido a electroforesis en geles de $1 \%$ de agarosa (Boehringer Mannheim Cat. 100439) y el fragmento de 902 pares de bases fue purificado a partir del gel, utilizando el GFX PCR DNA and Gel Band Purification Kit (Amersham Pharmacia Biotech), de acuerdo con las especificaciones de la compañía. Dos regiones del fragmento fueron secuenciadas en un secuenciador automático Abiprism 310 (Applied Biosystems), utilizando los iniciadores $G$ y $L$ descritos anteriormente. Una de las regiones en mención se denomina la región $G$, la cual se secuenció utilizando el iniciador $\mathrm{G}$. Esta se compone de 147 nucleótidos y codifica los aminoácidos 467-514 de la proteína $G$ del virus. La otra se denomina la región Psi-L, la cual se secuenció utilizando el iniciador L. Ésta consta de 258 nucleótidos en total, 174 de ellos pertenecientes a la región intergénica no codificante G-L conocida como pseudogen Psi (21) y los 84 nucleótidos restantes, que codifican para los aminoácidos 1 a 28 de la proteína L. En cada corrida del secuenciador se incluyó, a manera de control, la cepa Pasteur (PV) de secuencia conocida, con el fin de validar las secuencias obtenidas para cada una de las cepas rábicas en estudio. Únicamente las secuencias con señal fuerte y clara se tuvieron en cuenta para el posterior análisis. El resultado de la secuenciación se verificó de manera individual para cada cepa, confrontando cuidadosamente la secuencia con el respectivo electrofluorograma obtenido.

\section{Análisis filogenético}

El alineamiento de las secuencias se hizo de manera individual sobre el computador en modo DOS y adicionalmente se utilizó el paquete de computador Clustal $X$ para alineamiento múltiple (23). Los análisis de secuencia y la construcción de árboles filogenéticos se hicieron utilizando el paquete de computador Phylip 3.52 (24) y el programa Treview, en los cuales se empleó un método ya antes utilizado para analizar la región del genoma rábico que se secuenció en el presente estudio (10). El método en mención es el Kimura biparamétrico y neighbor joining (25), combinado con un bootstrap de 500 repeticiones, con lo cual es posible calcular intervalos de confianza para dar apoyo estadístico a la topología de los árboles filogenéticos (26). El método Kimura biparamétrico es un método de distancia, el cual asume que todos los nucleótidos ocurren o pueden ocurrir en frecuencias iguales (25\%). Los dos parámetros que se utilizan en este método son: 1) la tasa de transiciones y 2) la tasa de transversiones; se asume que éstas ocurren con diferente frecuencia. De hecho está bien 
documentado que las transiciones (sustitución de purina por purina o de pirimidina por pirimidina) ocurren con mucha mayor frecuencia que las transversiones (sustitución de una purina por una pirimidina y viceversa) (27). Así, el método Kimura biparamétrico es de utilidad para el análisis de segmentos genómicos como las estudiados en este trabajo, los cuales están compuestos en su mayoría por regiones hipervariables (endodominio del gen G) y no codificantes (pseudogen Psi). Adicionalmente, neighbor joining es un método de distancia práctico para el diseño de árboles filogenéticos, que posee algunas ventajas sobre otros métodos. En lo referente a la velocidad computacional, este método es superior a la mayoría de métodos que actualmente se utilizan. De esta manera, es fácil, con un computador personal, manejar al mismo tiempo más de 100 secuencias. En lo referente a la consistencia de la topología de los árboles generados, el método (así como el minimum evolution y mínimos cuadrados) producen topologías consistentes siempre y cuando se usen métodos no sesgados de sustitución de nucleótidos como medidas de distancia (como el Kimura biparamétrico). En general, la consistencia de la topología de los árboles decrece a medida que aumenta la longitud de las secuencias a ser analizadas, así, se nota una baja en la consistencia de las topologías cuando el número de nucleótidos de las secuencias excede los mil. Las pruebas estadísticas del método neighbor joining están ya bien establecidos y uno de los más utilizados es el bootstrap de Felsenstein, el cual fue utilizado en este trabajo. Entre los métodos de filogenia que producen una mejor confiabilidad en lo referente a la longitud de las ramas en los árboles filogenéticos, se encuentran algunos de los más conocidos como el de maximum likelighood, mínimos cuadrados, minimum evolution y neighbor joining (27).

\section{Resultados}

En primer lugar, las secuencias de nucleótidos de las regiones $G$ y Psi-L se analizaron por separado para poder comparar la información filogenética de cada una de estas regiones del genoma rábico. Sin embargo, como las dos regiones produjeron similares cladogramas, las secuencias de nucleótidos de las regiones $G$ y Psi-L fueron unidas como si se tratara de un solo fragmento para producir un único árbol filogenético; un raciocinio similar se ha aplicado en anteriores estudios (10). De acuerdo con la alineación de las secuencias de nucleótidos de las regiones $G$ y Psi-L (figuras 2 y 3 ), y con el análisis filogenético (figura 4), la muestra de estudio pudo distribuirse en tres grupos diferentes (figura 1). La variante genética colombiana I estuvo representada en este estudio por 21 cepas, 7 de las cuales fueron aisladas de perros domésticos en el departamento de Arauca en el periodo entre febrero de 1995 y marzo de 1997, y las 14 restantes de individuos de la misma especie en la Región Central, departamentos de Boyacá y Cundinamarca, en el periodo entre septiembre de 1994 y julio de 1996. La identidad de nucleótidos encontrada entre los virus de variante genética colombiana I fue en promedio $98 \%$, lo que muestra la estrecha relación que existe entre éstos. Los resultados muestran también un alto nivel de identidad de nucleótidos (promedio de 97,5\%) entre los virus que fueron aislados en la Región Caribe (de aquí en adelante llamados virus de variante genética colombiana II). En este estudio, la variante genética colombiana II estuvo representada por 43 cepas aisladas de 38 perros domésticos y 5 humanos, en el periodo entre agosto de 1994 y abril de 2002. Al examinar las secuencias de nucleótidos de las variantes genéticas colombianas I y II fue posible notar que éstas se definen y distinguen por sustituciones en 9 de los 147 nucleótidos de la región $\mathrm{G}$ y en 8 de los 258 nucleótidos de la región Psi-L (figuras 2 y 3 ). Al comparar las variantes genéticas colombianas I y II, la identidad de nucleótidos fue de $92,5 \%$ en promedio. En cuanto a los aminoácidos, las variantes genéticas colombianas I y II se distinguieron por sustituciones en cuatro de los 48 residuos codificados en la región $\mathrm{G}$ (aminoácidos 467 a 514 de la proteína $\mathrm{G}$ ). En contraste, la secuencia de aminoácidos codificada por la región Psi-L, correspondiente a los residuos 1 a 28 de la proteína $L$, fue idéntica para los virus de ambas variantes (figura 3), esto a pesar de que existen 8 sustituciones a nivel del ARN. Un tercer grupo de virus estuvo compuesto por 6 cepas, dos de las cuales fueron aisladas de dos murciélagos 
Región G: nucleótidos 4721-4867 del genoma del virus rábico:

A) Variante colombiana I tCCtgAttgC CCtgAtgtTg AtAAtTtTCC tAAtgAcAtg tTgtAgGAgA

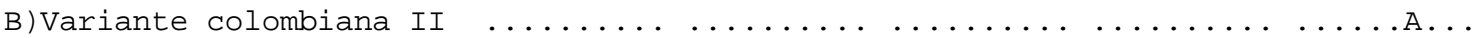

C) Variantes de rabia paresiante:

Cepa H03/97

Cepa B01/95

Cepa B01/00

Cepa C23/97

Cepa $\mathrm{C} 27 / 97$

Cepa C31/97

Murciélago insectívoro

$\ldots \ldots \ldots \ldots \ldots \ldots \ldots$....... T CG...... C...G.A..

СТ..GС.. А...ТС .... . . ...... .....

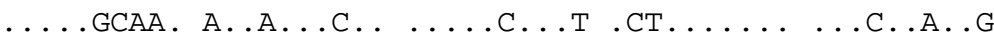

$\ldots$...... A........ .T..C.G.T C...G..A. C...G...

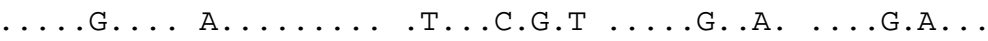

$\ldots \ldots \ldots$ A...........G.T ..............

Morimoto et al 1996

A) Variante colombiana I

B) Variante colombiana II

GTTAATCGAC CAgAATCTAT GCAACGAAGT CTCGGAgGGA CAgAgAgGAA

C) Variantes de rabia paresi

.C........... . . .......... TG.G...

Cepa H03/97

Cepa B01/95

.C...... ......A.G AAG...G.. TCT.A...T .G.GA.A..

Cepa B01/00

Cepa C23/97

Cepa $\mathrm{C} 27 / 97$

Cepa C31/97

Murciélago insectívoro

.CC..AA..A ....G..A.. A.G...G. TCTC.G.A.T .A.A....

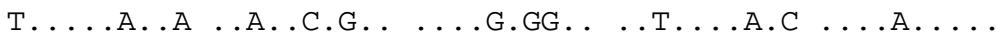

.C...GA..A ..C.G..A.A AAG....G. TCT.A...T..G.GA.A..

.C......A ....G..A.A A.G...G.С TCT.A...T..GAGA.A..

.C...G...A ..C.G..AGA CAG...G.C TCT.A.A.T ...GA.A...

Morimoto et al 1996

A) Variante colombiana I

GGTGTCGGTC ACCTCCCAAA GCGgGAAGgT CATATCTTCA TGGGAGT

B) Variante colombiana II

C) Variantes de rabia paresiante:

Cepa H03/97

Cepa B01/95

Cepa B01/00

Cepa C23/97

Cepa C27/97

Cepa C31/97

Murciélago insectívoro

Morimoto et al 1996

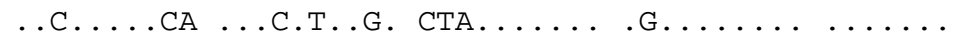

А..С.А.А С.ТС.Т... А....А. ....... ....

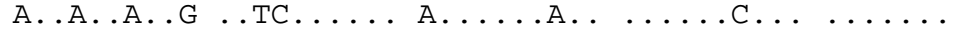

...А...СА ..TC.T..G. СТА...............

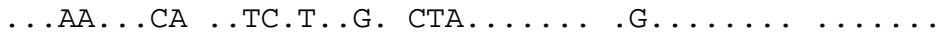

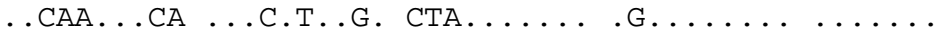

A......А G..С.T... А....АA. ...........

Secuencia de aminoácidos 467-514 de la proteína G:

A) Variante colombiana I LIALMLIIFLMTCCRRVNRPESMQRSLGGTGRKVSVTSQSGKVISSWE

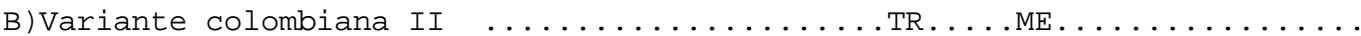

C) Variantes de rabia paresiante:

Cepa H03/97

Cepa B01/95

Cepa B01/00

Cepa C23/97

Cepa $\mathrm{C} 27 / 97$

Cepa C31/97

Murciélago insectívoro

......CS.A..G.AK.T..RR.GS..S.K.A.A.P.TR..V...

.A..I.........AK.T..IR.GSRESK ..P.PP.N ....P.

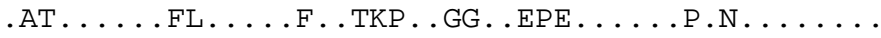
.V........AS.G.AK.TQ.KR.GS..S.K.ATA.P.TR..V...Q .V...... . .AS.G.AK.T..KR.GS .SRK..TA.P.TR..V.P. . ........A..G.AK.TQ.DR.GS.ES.K.ATA.P.TR..V... Morimoto et al 1996

Figura 2. Alineamiento de los nucleótidos 4721-4867 (región G) del genoma de los virus de la rabia y de los aminoácidos 467514 de la proteína $G$ nativa. A) Secuencia prototipo de la variante genética colombiana I. B) Secuencia prototipo de la variante genética colombiana II. C) Secuencias de las variantes de rabia paresiante estudiadas, en la que fue incluida una variante aislada de un murciélago insectívoro norteamericano de la especie Lasionycteris noctivagans. 
Región PSI-L: nucleótidos 5242-5500 del genoma del virus rábico:

A) Variante colombiana I AAGAGGCAAT CTGCCTCCCA TGAAGGACAT AAGCAATAGC TCATAATCAT

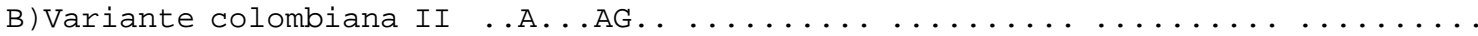

C) Variantes de rabia paresiante:

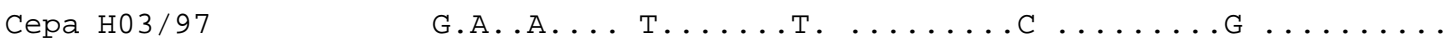

Cера B01/95 G..А.T... ..... ...... T............

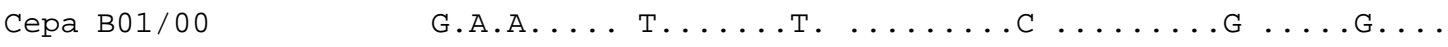

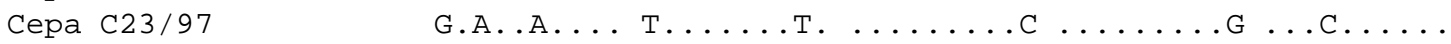

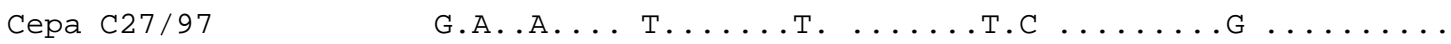

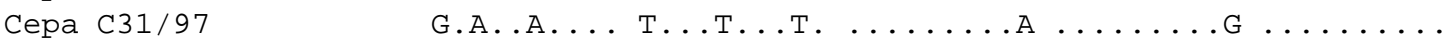

A) Variante colombiana I TtTGCAtCTC AgtAAAgtgt ACATAATtGT AAAgGgCtgG GTCATCTAAG

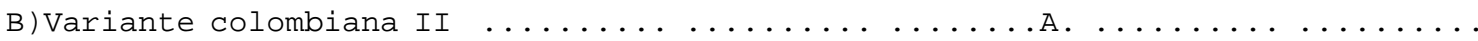

C) Variantes de rabia paresiante:

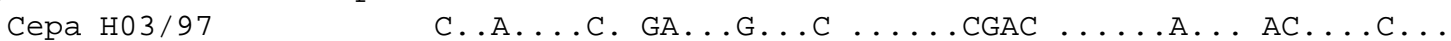
Cepa B01/95 C..A..... GA..G... ......AC ...... AC..... Сepa B01/00 ….... . GA..........GAC .............

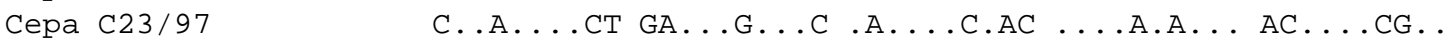

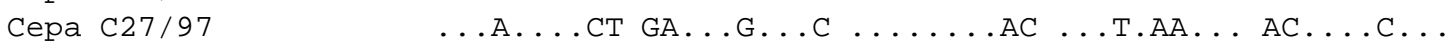

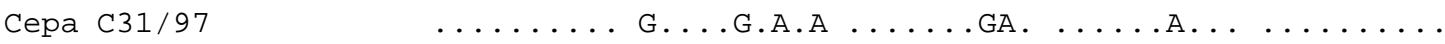

A) Variante colombiana I CATTTCAGTC GAgAAAAAAA CTGTAAACCA GAAGAGCAAC TAGCAACACT

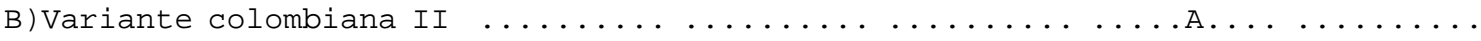

C) Variantes de rabia paresiante:

Cepa H03/97 .C.....................T..... С .....

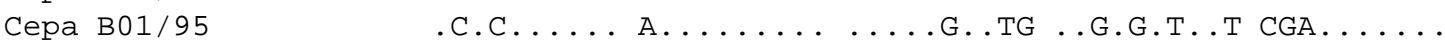
Cepa B01/00 .T.................GG.ATG A.G..T....AT...TC Cepa C23/97 Cepa $\mathrm{C} 27 / 97$ Cepa C31/97 . C............... . . . . . . . . . . . .Т...А. А............ Т.......... $\ldots \ldots \ldots \ldots \ldots \ldots \ldots \ldots \ldots \ldots$. . . . . . . . . . .

A) Variante colombiana I TCTCATCCTG AGACCCGCAT CAAGATGCTA GATCCAGGGG AAgTCTACGA

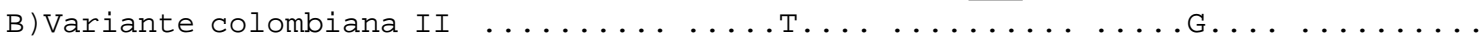

C) Variantes de rabia paresiante:

Cepa H03/97

Cepa B01/95

Cepa B01/00

Cepa C23/97

Cepa C27/97

Cepa C31/97

A) Variante colombiana I

$\ldots \ldots \ldots \ldots$. . . . . . . . . . . .G..TT.

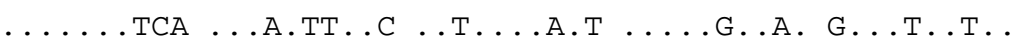

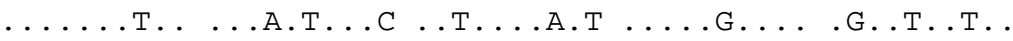

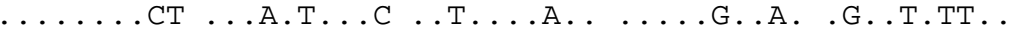

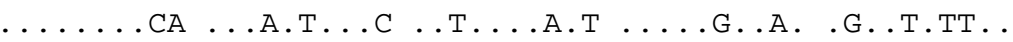

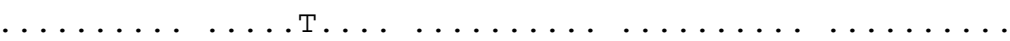

I TGACCCTATC GATCCAATCG AgtCAgAgGC TGAACCCAGA GGAgCCCCCA

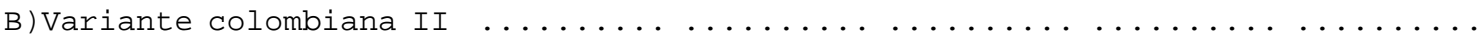

C) Variantes de rabia paresiante:

Cepa H03/97

Cepa B01/95

Cepa B01/00

Cepa C23/97

Cepa C27/97

Cepa C31/97

C.......................GT.G....GA....

$\ldots \ldots$. . . . . . . . . . . . . . . . . . .

$\ldots \ldots \ldots$. ..... . . ...............GAA.T..

C................... C..GT.G.......

C..................... C..GT.G.......

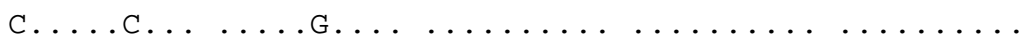

A) Variante colombiana I CTGTCCCC

B) Variante colombiana II .A..... 
C) Variantes de rabia paresiante

\begin{tabular}{|c|c|c|}
\hline Cepa & $\mathrm{HO} 3 / 97$ &.$C A \ldots$ \\
\hline Cepa & $\mathrm{B} 01 / 95$ & .A..... \\
\hline Cepa & B $01 / 00$ &.$A \ldots \ldots$ \\
\hline Cepa & C23/97 & . C... \\
\hline Cepa & C27/97 &.$C \ldots \ldots$ \\
\hline Cepa & C31/97 &.$A \ldots \ldots$ \\
\hline
\end{tabular}

Secuencia de aminoácidos 1-28 de la proteína L:
A) Variante colombiana I MLDPGEVYDDP IDPIESEAEPRGAPTVP

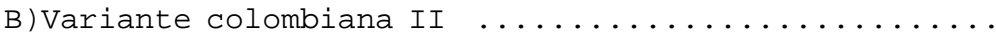
C) Variantes de rabia paresiante:
Cepa H03/97
Cepa B01/95
Cepa B01/00
Cepa C23/97
Cepa C27/97
Cepa C31/97

$$
\begin{aligned}
& \text {................... T. } \\
& \text {.I.................. } \\
& \text {. I................. } \\
& \text {. I....F...R.....S.... } \\
& \text {.I...F. . . . . . . . . . }
\end{aligned}
$$

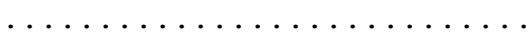

Figura 3. Alineamiento de los nucleótidos 5242-5500 (región Psi-L) del genoma de los virus de la rabia y de los aminoácidos 1-28 de la proteína $L$ nativa. A) Secuencia prototipo de la variante genética colombiana I. B) Secuencia prototipo de la variante genética colombiana II. C) Secuencias de las variantes de rabia paresiante estudiadas. El codón de iniciación de la proteína $\mathrm{L}$ se muestra dentro de una caja.

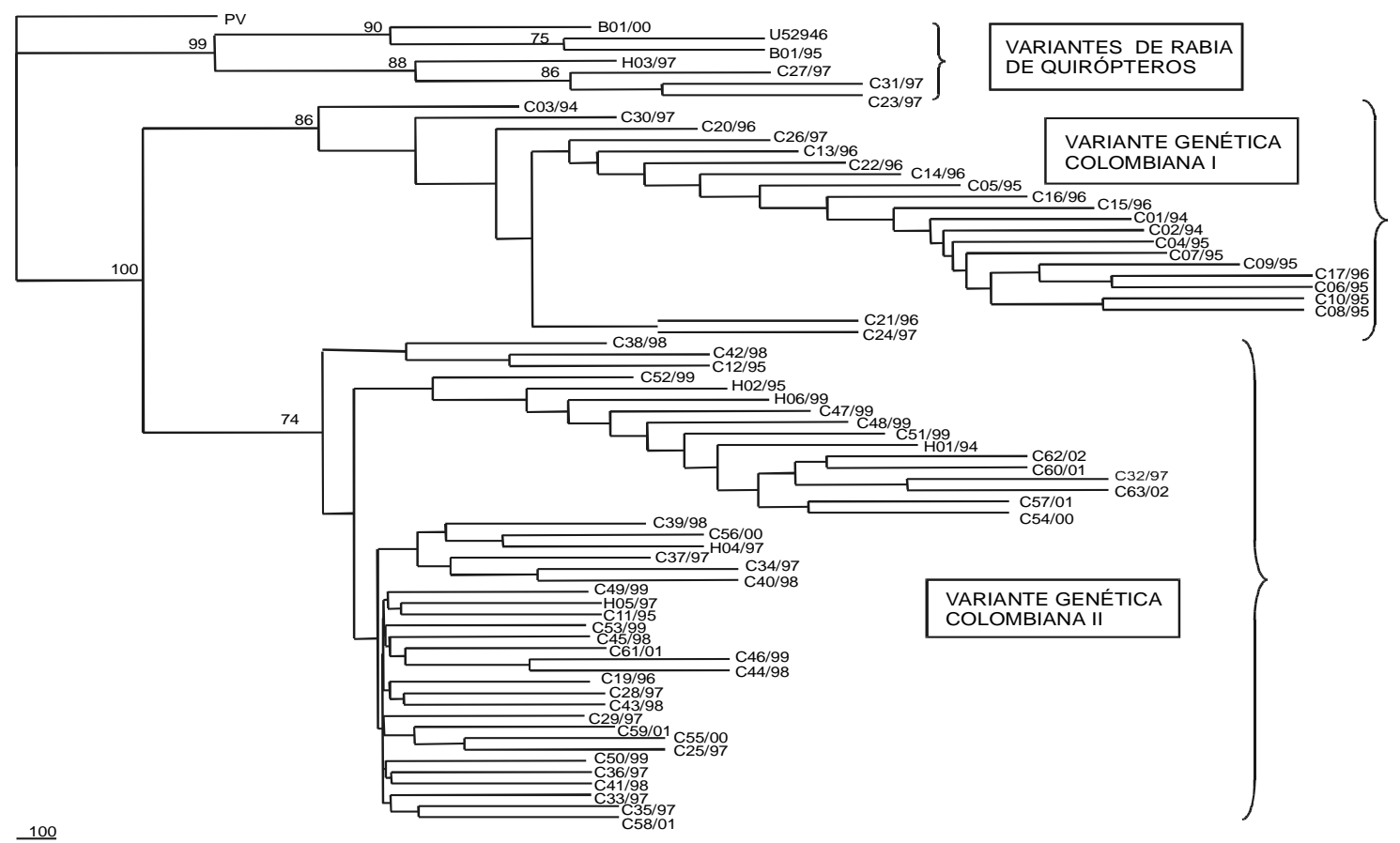

Figura 4. Relaciones filogenéticas de 72 cepas de rabia, de las cuales 68 fueron aisladas durante tres epizootias en Colombia. Este dendrograma está basado en la combinación de las secuencias de nucleótidos de las regiones G y Psi-L. La distancia genética se midió por el método de Kimura biparamétrico y neighbor joining, utilizando el programa Phylip 3.52. La cepa Pasteur (PV) se usó como el grupo externo. Los números en cada nodo indican los límites de confidencia que son mayores al $70 \%$. 
insectívoros de las especies Molossus molossus y Eptesicus braziliensis en alrededores de la ciudad de Cali en 1995 y 2000. Otras 3 cepas fueron aisladas en 1997 en perros domésticos en el departamento de Arauca, la Región Caribe, departamento de Cesar, y la Región Central, departamento de Tolima. La cepa restante fue aislada de un humano en el departamento de Bolívar en 1997. De acuerdo con los análisis filogenéticos y de secuencia, estas 6 cepas corresponderían a variantes de rabia paresiante (aquélla cuyos reservorios y transmisores son los quirópteros). La identidad de nucleótidos encontrada para las regiones $\mathrm{G}$ y Psi-L entre estas cepas fue de $83 \%$ en promedio, aunque tres de ellas (C23/97, C27/97 y C31/97) se encontraron cercanas, con una identidad de nucleótidos del $91 \%$ en promedio, valor que, si bien es alto, no es suficiente para agruparlas dentro de una variante genética. La cepa H03/97 se encuentra algo más alejada de las tres cepas anteriores y al compararse con éstas presentó una identidad de nucleótidos del $87 \%$. Por lo demás, las cepas B01/ 95, B01/00 y U52946, al compararse con el resto del grupo, presentaron una identidad de nucleótidos del $80 \%, 75 \%$, y $70 \%$, respectivamente, indicando que su distancia genética, entre sí y entre éstas y las otras del grupo, fue considerable. Teniendo en cuenta todo lo anterior, las 6 cepas de rabia paresiante $(\mathrm{HO} /$ 97, C23/97, C27/97, C31/97, B01/95 y B01/00) constituirían seis variantes distintas en este estudio. La identidad de nucleótidos encontrada entre las variantes de rabia paresiante y las variantes genéticas colombianas I y II fue de $72 \%$ y $73 \%$ en promedio respectivamente.

\section{Discusión}

Durante la década de 1980 , la rabia urbana se extendió a lo largo de la Región Central y el departamento de Arauca sobre 19.000 y 8.000 $\mathrm{km}^{2}$, respectivamente. Los resultados que se presentan en este artículo indican que los virus rábicos que se transmitieron en estas dos epizootias estaban estrechamente relacionados desde el punto de vista genético, con una identidad de nucleótidos promedio del $98 \%$. Es por lo anterior que estos virus fueron agrupados dentro de lo que se llamó la variante genética colombiana I. Las epizootias de rabia urbana en la Región Central y en el departamento de Arauca finalizaron en 1997. No se han aislados virus rábicos de variante genética colombiana I desde ese año, lo cual sugiere que éstos no originaron ningún otro brote y se encuentran extintos en el territorio colombiano. Las campañas de erradicación de la rabia, que incluyen el control y vacunación de la población canina, deben haber jugado un importante papel en la supuesta extinción de los virus rábicos de variante genética colombiana I $(4,5)$.

Durante la década de 1990, otra epizootia de rabia urbana se extendió a lo largo de aproximadamente $40.000 \mathrm{~km}^{2}$ de la Región Caribe colombiana, departamentos de Atlántico, Bolívar, Cesar, Córdoba, Magdalena y Sucre. A pesar de las campañas de control y vacunación de caninos, la rabia urbana, aunque ha disminuido considerablemente en los últimos meses, representa todavía un grave problema de salud pública en la Región Caribe colombiana y podría, eventualmente, extenderse a otras regiones en Colombia $(4,5)$. Nuestros resultados muestran que los virus transmitidos en esta región están genéticamente relacionados, por lo que fueron agrupados en una sola variante que se denominó en este estudio variante genética colombiana II. Actualmente, los virus de la variante genética colombiana II se encuentran restringidos a la Región Caribe, específicamente al departamento de Magdalena y, en menor grado, a Atlántico y Sucre. Gracias a los programas de vacunación, estos virus están en proceso de erradicación en Colombia, lo cual se deduce de la notable disminución del número de casos de rabia urbana informados en el año 2002 ( 16 casos en el periodo enero-diciembre). El hecho de que la rabia se transmita de quirópteros a humanos, causándoles la muerte, ha sido ampliamente documentado (2831). En nuestra muestra de estudio se encontraron 4 cepas rábicas (H03/97, C23/97, C27/97 y C31/ 97), aisladas de un humano y tres perros, que están genéticamente relacionadas con 3 cepas rábicas aisladas directamente de quirópteros: $\mathrm{B} 01 /$ 95 y B01/00, aislados respectivamente de murciélagos insectívoros Molossus molossus y 
Eptesicus braziliensis en el Valle del Cauca, y una cepa (genebank U52946) aislada en Estados Unidos de un murciélago insectívoro Lasionycteris noctivagans, especie que constituye una de las principales fuentes de infección en casos de rabia humana en ese país (28). Lo anterior indica que, aunque pertenecientes a variantes genéticas distintas, H03/97, C23/97, C27/97 y C31/97 habrían tenido origen en quirópteros y convierte el presente estudio en el primero en Colombia que asocia la rabia en caninos y humanos con quirópteros, identificando así a estos últimos como reservorios que constituyen una amenaza para la salud pública en el país. Ya se han informado casos de rabia humana transmitida por murciélagos en algunos países de América como Chile (32,33), Perú (30) y Estados Unidos (34). Al examinar las secuencias rábicas estudiadas, se observa que existen más sustituciones de nucleótidos en la región $\mathrm{G}$ que en el fragmento del pseudogen Psi secuenciado, esto a pesar de la naturaleza no codificante de este último, que lo convierte en una región aceptora de sustituciones espontáneas $(2,8,21)$. La aparente discrepancia se explica de la siguiente manera: el gen $G$ es una región altamente variable, debido a la deriva antigénica a la que se encuentra expuesta la proteína $\mathrm{G}(2,35)$, a su vez, el endodominio es la región más variable dentro del gen $G$ (35). Adicionalmente, la región central de Psi es el doble de variable que los flancos (10). En estudios anteriores en cepas rábicas surafricanas, se observó variabilidad similar entre el endodominio del gen G y Psi (10). Luego, es coherente que aparezcan más sustituciones en el endodominio del gen $G$ que en la región menos variable dentro de Psi.

\section{Agradecimientos}

El presente estudio fue realizado en el Laboratorio de Virología del Instituto Nacional de Salud en Bogotá y financiado por el Ministerio de Salud de Colombia (convenio 689 de 1999), la Fundación Saldarriaga Concha (convenio 011-99 INS-SANUT) y el Banco de la República (contrato 200005). Los autores de este artículo desean agradecer a Carlos Alvarez, Vladimir Corredor y Luis Murillo, del antiguo Instituto de Inmunología en Bogotá, y a Ignacio Sarante, del Instituto de Genética de la
Universidad Javeriana en Bogotá, por su útil asistencia en los procesos de RT-PCR, secuenciación y análisis filogenético. Los autores también desean agradecer a Noel Tordo, Hassan Badrane y Herve Bourhy, del Instituto Pasteur en París, por su útil asistencia en el análisis filogenético y en la preparación del manuscrito, así como a Carlos Arturo Hernández, Gabriel Perdomo y Francisco Rodríguez de la División de Biblioteca y Publicaciones del Instituto Nacional de Salud, por su valiosa colaboración en la preparación del material gráfico.

\section{Referencias}

1. Beran GW, Steele JH. Viral zoonoses. En: Beran GW, Steele JH, editors. Handbook of zoonoses. Boca Ratón: CRC Press; 1994. p.307-57.

2. Wunner WH, Larson JK, Dietzschold B, Smith CL. The molecular biology of rabies virus. Rev Infect Dis 1988;10:771-84.

3. Tordo N, Kouknetzoff A. The rabies virus genome: an overview. Onderstepoort J Vet Res 1994;67:45-9.

4. Rico A, Díaz A, Rico E. Informe de la rabia urbana en Colombia, 1996-2001. Bogotá: Programa de Zoonosis, Ministerio de Salud de la República de Colombia; 2001.

5. Ministerio de Salud, Instituto Nacional de Salud. Rabia. Quinta edición. Serie de notas e informes técnicos No. 4. Bogotá: Ministerio de Salud, Instituto Nacional de Salud; 1995

6. Favi M, Durán JC. Epidemiología de la rabia en Chile (1929-1988). Avances en Ciencias Veterinarias 1991;6: 13-21.

7. Favi M, Yung V, Pavletic C. Programa de vigilancia y control de la rabia en Chile. Laboratorio al Día 1997;13: 18.

8. Sacramento D, Badrane H, Bourhy H, Tordo N. Molecular epidemiology of rabies virus in France: comparison with vaccine strains. J Gen Virol 1992;73: 114958.

9. Nadin-Davis S, Casey GA, Wandeler I. A molecular epidemiological study of rabies virus in central Ontario and western Quebec. J Gen Virol 1994;75:2575-83.

10. von Teichman BF, Thomson GR, Meredith CD, Nel LH. Molecular epidemiology of rabies virus in South Africa: evidence for two distinct virus groups. J Gen Virol 1995;76:73-82.

11. de-Mattos C, de-Mattos C, Smith JS, Miller ET, Papo $\mathrm{S}$, Utrera A, et al. Genetic characterization of rabies field isolates from Venezuela. J Clin Microbiol 1996;34: 1553-8. 
12. Smith JS, Orciari LA, Yager PA, Seidel HD, Warner CK. Epidemiologic and historical relationships among 87 rabies virus isolates as determined by limited sequence analysis. J Infect Dis 1992;166:296-307.

13. Rohde RE, Neil SU, Clark KA, Smith JS. Molecular epidemiology of rabies epizootics in Texas. Clin Diagnos Virol 1997;8:209-17.

14. Rupprecht CE, Smith JS, Krebs JW, Childs JE. Molecular epidemiology of rabies in the United States: reemergence of a classical neurotropic agent. J Neurovirol 1997;3:s52-3.

15. Ito N, Sugiyama M, Oraveerakul K, Piyaviriyakul $\mathbf{P}$, Lumlertdacha B, Arai YT, et al. Molecular epidemiology of rabies in Thailand. Microbiol Immunol 1999;43:551-9.

16. David T, Yakobson B, Smith JS, Starm Y. Molecular epidemiology of rabies virus isolates from Israel and other middle and near-eastern countries. J Clin Microbiol 2000;38:755-62.

17. Heinemann MB, Fernandes-Matioli FM, Cortez A, Soares RM, Sakamoto SM, Bernardi F, et al. Genealogical analyses of rabies virus strains from Brazil based on N gene alleles. Epidemiol Infect 2002;128: 503-11.

18. Wright A, Rampersad J, Ryan J, Ammons D. Molecular characterization of rabies virus isolates from Trinidad. Vet Microbiol 2002;87:95-102.

19. Koprowski H. Prueba de inoculación en ratones. En: Organización Mundial de la Salud. Técnicas de laboratorio aplicadas a la rabia. Serie de monografías No. 23. Washington, D.C.: Oficina Sanitaria Panamericana; 1956. p. 57-69.

20. Páez A, García C, Boshell J. Estandarizacion de la obtencion de amplficados del genoma del virus de la rabia para su uso en estudios de epidemiologia molecular. Biomédica 2002;22:71-6.

21. Tordo N, Poch O, Ermine A, Keith G, Rougeon F. Walking along the rabies genome: is the large G-L intergenic region a remnant gene? Proc Natl Acad of Scien USA 1986;83:3914-8.

22. Tordo N, Poch O, Ermine A, Keith G, Rougeon F. Completion of the rabies virus genome sequence determination: highly conserved domains among the $L$ (polymerase) proteins of unsegmented negative-strand RNA viruses. Virology 1988;165:565-76.

23. Thompson JD, Gibson TJ, Plewniak F, Jeanmougin F. Higgins DG. The ClustalX windows interface: flexible strategies for multiple sequence alignment aided by quality analysis tools. Nucl Ac Res 1997;24:4876-82.

24. Felsestein J. PHYLIP: phylogeny inference package 3.52c. Washington, D.C.: University of Washington; 1993.

25. Saitou N, Nei $\mathbf{M}$. The neighbor-joining method: a new method for reconstructing phylogenetic trees. Mol Biol Evol 1987;4:406-25.

26. Nei M. Relative efficiencies of different tree-making methods for molecular data. En: Miyamoto MM, Cracraft $\mathrm{J}$, editors. Phylogenetic Analysis of DNA sequences. New York: Oxford University Press; 1992. p.90-129.

27. Nei M. Phylogenetic analysis in molecular evolutionary genetics. Ann Rev Gen 1996;30:371-403.

28. Morimoto K, Patel M, Corisdeo S, Hooper DC, Fu ZF, Rupprecht CE, et al. Characterization of a unique variant of bat rabies virus responsible for newly emerging cases in North America. Proc Natl Acad Scien USA 1996; 93:5653-8.2

29. Crawford-Miksza LK, Wadford DA, Schnurr DP. Molecular epidemiology of enzootic rabies in California. $\mathrm{J}$ Clin Virol 1999;14:207-19.

30. Warner CK, Zaki SR, Shieh WJ, Whitfield SG, Smith JS, Orciari LA, et al. Laboratory investigation of human deaths from vampire bat rabies in Perú. Am J Trop Med Hyg 1999;60:502-7.

31. Madsen PL. Danger from rabies-infected bats. Lancet 2000;355:934.

32. Favi M, Yung V, Pavletic C, Ramirez E, de Mattos CC, de Mattos CA. Rol de los murciélagos insectívoros en la transmisión de la rabia en Chile. Archivos de Medicina Veterinaria 1999;31:157-65.

33. Favi M, de Mattos CA, Yung V, Chala E, Lopez LR, de Mattos CC. First case of human rabies in Chile caused by an insectivorous bat virus variant. Emerg Infect Dis 2002;8:79-81.

34. Messenger SL, Smith JS, Rupprecht CE. Emerging epidemiology of bat-associated cryptic cases of rabies in humans in the United States. Clin Infect Dis 2002;35: 738-47.

35. Benmansour A, Brahimi M, Tuffereau C, Coulon P, Lafon F, Flamand A. Rapid sequence evolution of rabies glycoprotein is related to the highly heterogeneous nature of the viral population. Virology 1992;187:33-45. 